\title{
Elimination of Bisphenol A from Wastewater through Membrane Filtration Processes
}

\author{
Mariusz Dudziak ${ }^{1 *}$, Edyta Kudlek', Edyta Łaskawiec ${ }^{1}$, Ewa Felis², \\ Katarzyna Kowalska², Leon Garbaczewski ${ }^{3}$ \\ 1 Silesian University of Technology Institute of Water and Wastewater Engineering Konarskiego 18, 44-100 \\ Gliwice, Poland \\ 2 Silesian University of Technology Environmental Biotechnology Department Akademicka 2, 44-100 Gliwice, \\ Poland \\ 3 Talmex sp. z 0.o. Chopina 94, 43-600 Jaworzno, Poland \\ * Corresponding author's e-mail: mariusz.dudziak@polsl.pl
}

\begin{abstract}
New priorities for the environment have resulted in a reassessment of modern technology for treatment of urban wastewater. Urban wastewater treatment mainly involves the elimination or reduction of anthropogenic organic micropollutants in the aquatic environment. In this paper, the effectiveness of bisphenol A elimination from wastewater, after biological treatment, through a complex ultrafiltration/reverse osmosis purification process was evaluated. The effectiveness of the wastewater treatment process in the tested system was also evaluated with a number of other physical and chemical analyses for $\mathrm{pH}$, turbidity, colour, absorbance, TOC, phenol index, conductivity and the concentration of selected heavy metals. Within this study, the change in the hydraulic performance of the membranes was also investigated. The effectiveness of the reduction of bisphenol A concentrations during the process of ultrafiltration was small, due to the significant difference between the size of the pores of the membrane and the size of eliminated micropollutants. In the process of reverse osmosis, the wastewater treatment system reported that the concentration of bisphenol A was reduced by $68 \%$. In the tested treatment system, the ultrafiltration/reverse osmosis completely removed colour, lead and chromium. Other contaminants were eliminated by more than $31 \%$. In both membrane processes, there was evidence that the membrane pores were blocked, but this occurred to a greater extent during the process of reverse osmosis.
\end{abstract}

Keywords: wastewater treatment, bisphenol A, ultrafiltration, reverse osmosis, complex purification process

\section{INTRODUCTION}

The modern technology for the treatment of urban wastewater through purification is being re-evaluated due to new environmental priorities, including the need for total elimination or reduction of anthropogenic organic micropollutants in the aquatic environment [Barbosa et. al. 2016; Grandclément et. al. 2017]. The need to eliminate or reduce the anthropogenic organic micropollutants is related to their biological activity, including their toxic effects on living organisms [Anderson et al. 2015].
For wastewater treatment after biological purification processes, there are advanced oxidation processes (ozonation, photocatalysis, et al.) [Giannakis et al. 2015; Kim and Zoh. 2016] and membrane filtration processes (microfiltration, ultrafiltration, nanofiltration and reverse osmosis) [Tang e al. 2016; Yu et al. 2017].

Due to its many advantages, such as high efficiency, simplicity, and convenient operation of devices, membrane filtration may be one of the most important separation techniques. However, its effective application still requires conducting basic research. This is the result of, among 
other factors, the issue involving the pores of the membrane being blocked during operation, which lowers the initial efficiency of the system [Tang et al. 2016]. The simplest solution is a combination of filtration at low and high pressures.

In this paper, the effectiveness of bisphenol A elimination from wastewater after biological treatment through a complex purification process of ultrafiltration/reverse osmosis is evaluated. Bisphenol A is commonly used in the production of plastics and epoxy resins, and it is an example of an anthropogenic micropollutant that is often identified in the aquatic environment [Deblonde et al. 2011]. The effectiveness of wastewater treatment processes for the test system has been evaluated with a number of other physical and chemical tests for $\mathrm{pH}$, turbidity, colour, absorbance, TOC, phenol index, conductivity and the concentration of selected heavy metals. Within this paper, the change in the hydraulic performance of membranes has also been investigated.

\section{MATERIALS AND METHODS}

The research was carried out by using the actual effluent from wastewater treatment plants after biological purification. A sample of selected anthropogenic micropollutants was added to the wastewater effluent, i.e., bisphenol A, at a concentration of $1000 \mu \mathrm{g} / \mathrm{L}$. The high concentration was added due to the increasing accuracy of the performed analytical measurements.

The characteristics of the wastewater, before and after the purification process, were determined on the basis of following measurements:

- general parameters, which describe the properties of the test stream, i.e., $\mathrm{pH}$, turbidity and colour;

- parameters associated with the presence of organic substances in the water (absorbance in $\mathrm{UV}_{254}$, total organic carbon TOC and phenol index);

- parameters associated with the presence of inorganic substances (conductivity);

- concentrations of organic micropollutants i.e., bisphenol A; and

- concentrations of heavy metals (zinc, cadmium, copper, lead, nickel, chrome, arsenic, selenium and mercury).

For the measurement of general parameters ( $\mathrm{pH}$ and temperature) and the specific conduc- tivity, a laboratory multi-parameter inoLab ${ }^{\circledR} 740$ meter, produced by WTW Measurement and Analytical Equipment Technology, was used. Absorbance was measured at a wavelength of $254 \mathrm{~nm}$, using a UV VIS Cecil 1000 manufactured by Analytik Jena AG, and the concentration of organic carbon was determined by means of TOC-L General Analyser, which was produced by Shimadzu. In order to determine the turbidity of the samples, a Turbidimeter TN-100, produced by EUTECH, was used. Colour measurement was performed by using a UV-VIS Spectroquant ${ }^{\circledR}$ Pharo 300 spectrophotometer that was produced by Merck, using a wavelength of $340 \mathrm{~nm}$. The UV-VIS spectrometer was also used to measure the phenol index, which was also measured by Merck's commercial tests.

Determination of heavy metals (zinc, cadmium, copper, lead, nickel, chrome, arsenic and selenium) was carried out by using optical emission spectrometry with excited plasma (ICPOES) ACC in compliance with the PN-EN ISO 11885:2009 standard, and in the case of mercury, atomic spectrometry was used, specifically the cold vapours (CV-AAS) ACC technique, in compliance with the PN-ISO 16772:2009 standard.

The concentration of bisphenol A was determined by using chromatography HPLC with UV detection after separation of the water sample analyte. For this purpose, solutions with a volume of $100 \mathrm{~mL}(\mathrm{pH}=7)$ were extracted to the solid phase (SPE). The column bed (Supelclean ${ }^{\mathrm{TM}}$ ENVI18 columns with a volume of $6 \mathrm{~mL}$ containing $1000 \mathrm{mg}$ of the phase and produced by Supelco, and an SPE pressure chamber, produced by the same company) was conditioned with acetonitrile and methanol before extraction, and then, it was washed with deionized water. The extracted compound was eluted by a mixture of acetonitrile with methanol $(40 / 60, \mathrm{v} / \mathrm{v})$ with a volume of 3 $\mathrm{mL}$. For the qualitative analysis of the extract, an HPLC, produced by Varian (UV detector, wavelength $235 \mathrm{~nm}$ ), was used. Chromatographic separation was performed on a column of $100 \mathrm{Mi}$ crosorb C18 (produced by Polygen) that was 25 $\mathrm{cm}$ long and was characterized by a diameter of $4.6 \mathrm{~mm}$ and graining of $5 \mu \mathrm{m}$. Acetonitrile made by $\mathrm{POCH}$, was used for the mobile phase. The applied analytical procedure is characterized by a recovery of bisphenol $\mathrm{A}$ at the level of $66 \%$, which was determined for the deionized water with a concentration of $500 \mu \mathrm{g} / \mathrm{L}$ (sample volume of $100 \mathrm{~cm}^{3}$ ) of the introduced compound pattern. The limit of detection for the method (for a signal to noise intensity equal to 10 ) was $2.0 \mathrm{ng} / \mathrm{L}$. 
Table 1 presents the physical characteristics of the actual wastewater effluent with the addition of bisphenol A. The tested effluent was a mixture of average day and night wastewater effluent. The concentration of micropollutants in the wastewater, before bisphenol A was added, was below the limit of detection, based on the applied analytical method. In the tested effluent, cadmium, arsenic and selenium were not detected. The effluent was collected from the municipal wastewater treatment plant located in Silesia Province. The raw wastewater at the treatment plant was a mixture of household and industrial waste. The mechanical-biological treatment process was based on the separation of solids suspended on grates and on the biological decomposition of organic compounds through dephosphatation and denitrification processes.

Membrane filtration was carried out in the cross-flow system by using tubular membranes made of different membrane materials (Table 2). The filtration system was made entirely of stainless steel and equipped with a tubular module adapted for polymer membranes with an active surface of $240 \mathrm{~cm}^{2}$, an intermediate tank of $15 \mathrm{~L}$, a high-pressure pump with a capacity of 0.5 to $3.0 \mathrm{~m}^{3} / \mathrm{h}$ (CRN 3) manufactured by the Grundfos company as well as control and measurement equipment. The pressure gauges were placed before and after the membrane module, and the flow meter was installed on the retentate line. The process pressure was adjusted by using an inverter, and the desired temperature was maintained by the heat exchanger, which was placed on the tank walls and along the entire length of the discharge line. The system could run low- and high-pressure processes.

The membrane filtration studies were carried out in the membrane conditioning sequence, using deionized water and by performing filtration of treated wastewater. Ultrafiltration was carried out at a transmembrane pressure of $0.2 \mathrm{MPa}$ and reverse osmosis at 2.0 $\mathrm{MPa}$. The temperature of the filtered wastewater in both processes was $20^{\circ} \mathrm{C}$.

In order to evaluate the effectiveness of the membrane process, the efficiency was determined by marking the volumetric flux of permeate $\left(\mathrm{J}, \mathrm{m}^{3} / \mathrm{m}^{2} \cdot \mathrm{s}\right)$ and retention/reduction $(\mathrm{R}, \%)$ of the selected pollutants or by general indicators related to the presence of individual groups of pollutants. The effect of membrane surface blocking was established by determining its relative permeability $(\alpha)$, which is the quotient of streams designated for a new membrane during its conditioning $\left(\mathrm{J}_{\mathrm{w}}\right)$ and after the process of wastewater treatment $\left(\mathrm{J}_{\mathrm{v}}\right)$.

Table 1. Physicochemical characterization of the effluent with bisphenol A

\begin{tabular}{|l|c|c|c|c|c|}
\hline \multicolumn{1}{|c|}{ Parameter } & Unit & Value & Parameter & Unit & Value \\
\hline $\mathrm{pH}$ & - & 7.50 & $\mathrm{Cd}$ & $\mathrm{mg} / \mathrm{L}$ & $<0.001$ \\
\hline Turbidity & $\mathrm{NTU}$ & 3.03 & $\mathrm{Cu}$ & $\mathrm{mg} / \mathrm{L}$ & 0.002 \\
\hline Color & $\mathrm{mg} \mathrm{Pt} / \mathrm{L}$ & 91.00 & $\mathrm{~Pb}$ & $\mathrm{mg} / \mathrm{L}$ & 0.002 \\
\hline Absorbance & $1 / \mathrm{cm}$ & 0.26 & $\mathrm{Ni}$ & $\mathrm{mg} / \mathrm{L}$ & 0.013 \\
\hline TOC & $\mathrm{mg} / \mathrm{L}$ & 20.42 & $\mathrm{Cr}$ & $\mathrm{mg} / \mathrm{L}$ & 0.002 \\
\hline Phenol index & $\mathrm{mg} / \mathrm{L}$ & 0.85 & $\mathrm{Hg}$ & $\mathrm{mg} / \mathrm{L}$ & 0.00008 \\
\hline Conductivity & $\mathrm{HS} / \mathrm{cm}$ & 768.50 & $\mathrm{As}$ & $\mathrm{mg} / \mathrm{L}$ & $<0.02$ \\
\hline Zn & $\mathrm{mg} / \mathrm{L}$ & 0.04 & $\mathrm{Se}$ & $\mathrm{mg} / \mathrm{L}$ & $<0.02$ \\
\hline
\end{tabular}

Table 2. Characteristics of UF and RO membranes

\begin{tabular}{|l|c|c|}
\hline \multicolumn{1}{|c|}{ Parameters } & UF membrane & RO membrane \\
\hline Membrane type & ES625 & AFC99 \\
\hline Manufacturer & PCI Membrane System Inc. & PCI Membrane System Inc. \\
\hline Membrane chemistry & polyethersulphone & composite \\
\hline Max temperature, ${ }^{\circ} \mathrm{C}$ & 80 & 80 \\
\hline Max operating pressure, $\mathrm{MPa}$ & 1.5 & 6.4 \\
\hline $\mathrm{pH}$ range & $1.5-12$ & $-1.5-12$ \\
\hline $\mathrm{MWCO}, \mathrm{Da}$ & 25000 & 99.0 \\
\hline $\mathrm{NaCl}$ rejection, $\%$ & - & - \\
\hline $\mathrm{MgSO}_{4}$ rejection, $\%$ & - & 0.024 \\
\hline $\mathrm{Membrane}^{2}$ surface area, $\mathrm{m}^{2}$ & 0.024 & - \\
\hline
\end{tabular}




\section{RESULTS AND DISCUSSION}

The initial membrane hydraulic capacity for reverse osmosis, with respect to the ultrafiltration membrane, was nearly half as high (Figure 1). This is because of the characteristics of the applied membranes (Table 2) as well as the value of the applied transmembrane pressure. The value of the received transmembrane pressure depends primarily on the type of membrane process as well as the recommendations of the membrane manufacturer.

Subsequently, the treated wastewater was subjected to purification through an integrated purification process of ultrafiltration/reverse osmosis. In the ultrafiltration process and reverse osmosis, a gradual reduction of membrane hydraulic capacity, which was caused by pore blocking phenomenon (Figure 2), was discovered. However, this was related to the process of reverse osmosis to a greater extent than the ultrafiltration. The blocking was due to the difference in the properties of the surface of the membranes used. The average value of the relative permeate stream $\alpha$ for an ultrafiltration membrane was 0.68 , whereas for a reverse osmosis membrane, it amounted to 0.59.

The effectiveness of the ultrafiltration process at decreasing bisphenol A concentrations was low, and it did not exceed a few percentage points due to the significant difference between the size of the pores of the membrane and the size of the eliminated micropollutants. A significant reduction in the concentration of bisphenol A resulted from the process of reverse osmosis (Figure 3). The tested compound was eliminated by more than $68 \%$. The better ability of reverse osmosis to remove compounds, which was noticed at the end

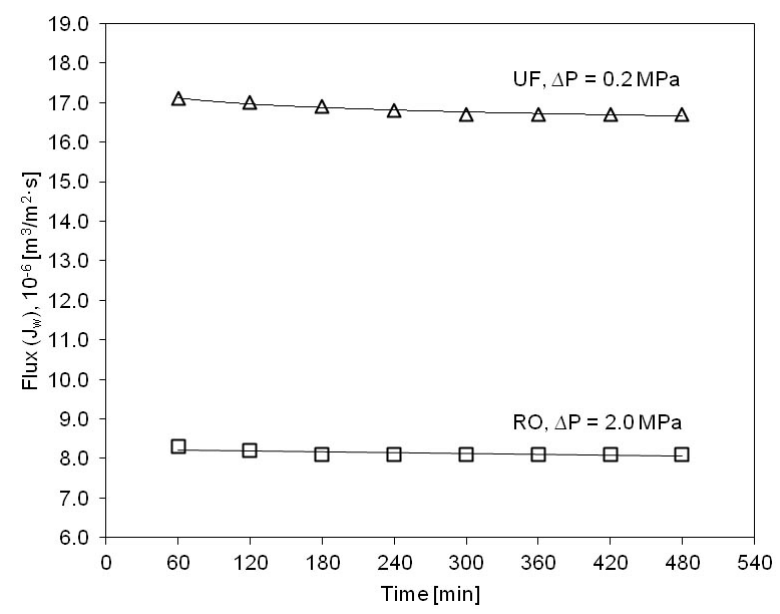

Figure 1. Permeate flux for new membrane of filtration, resulted from the secondary membrane having a lower porosity than the one of the original membrane [Grandclément et. al. 2017].

Subsequently, the elimination efficiency was evaluated in the studied sewage treatment system for other selected pollutants, which were general
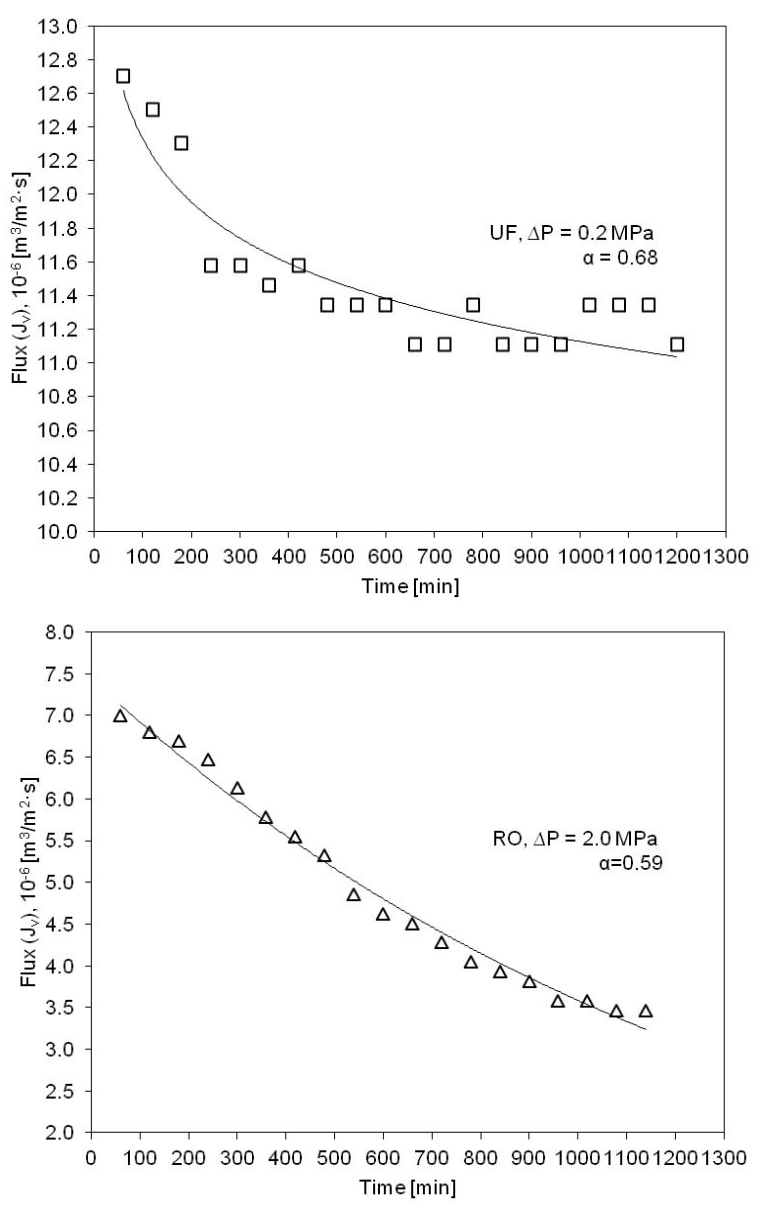

Figure 2. Permeate flux of membranes during wastewater treatment

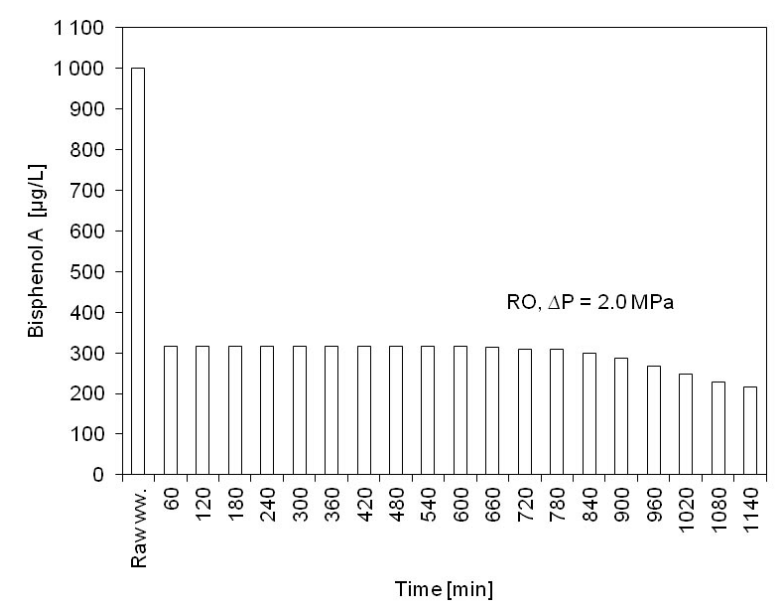

Figure 3. Changes in bisphenol A concentrations in permeate 
indicators related to the presence of individual groups of pollutants. It was concluded that with ultrafiltration, the turbidity, colour and absorbance in wastewater were significantly decreased (Figure 4). In addition, reverse osmosis enabled to remove wastewater colour completely. Absorbance and conductivity in wastewater (Figure 5) were also greatly decreased. In turn, the pollu-
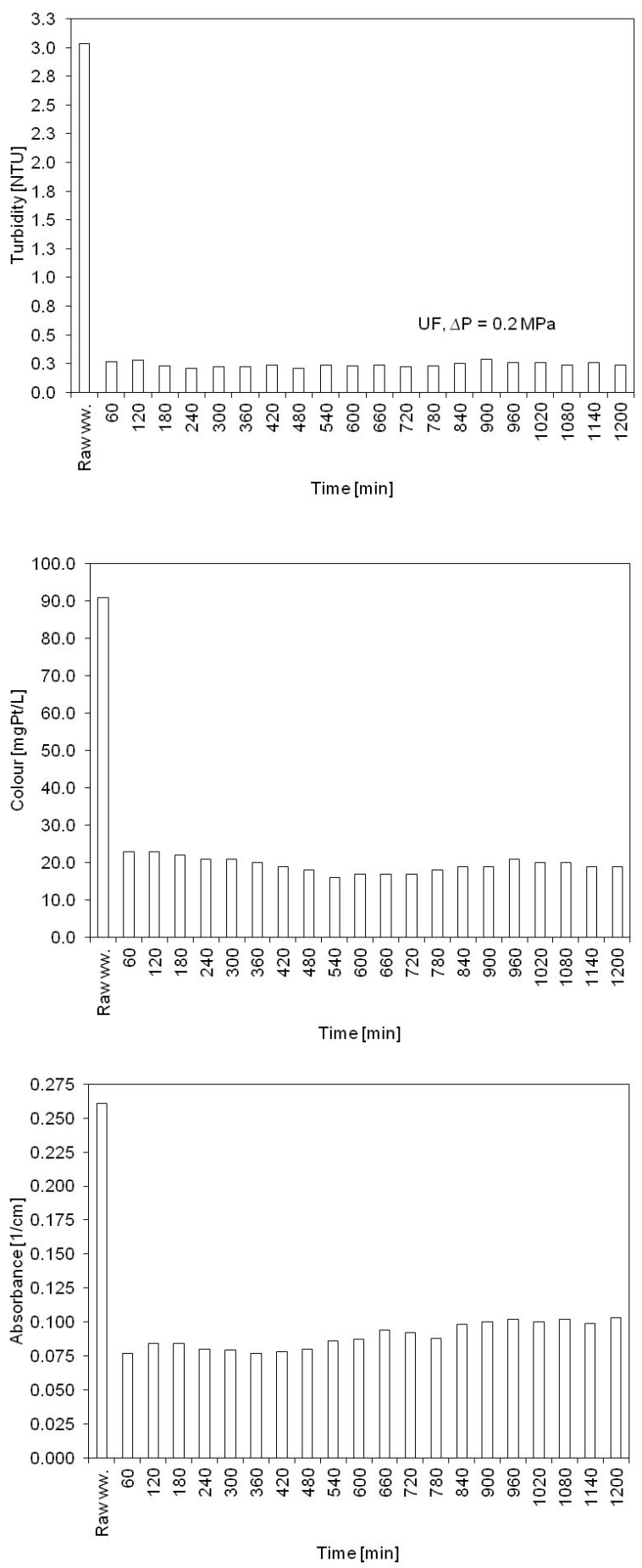

Figure 4. Efficiency of wastewater treatment through ultrafiltration
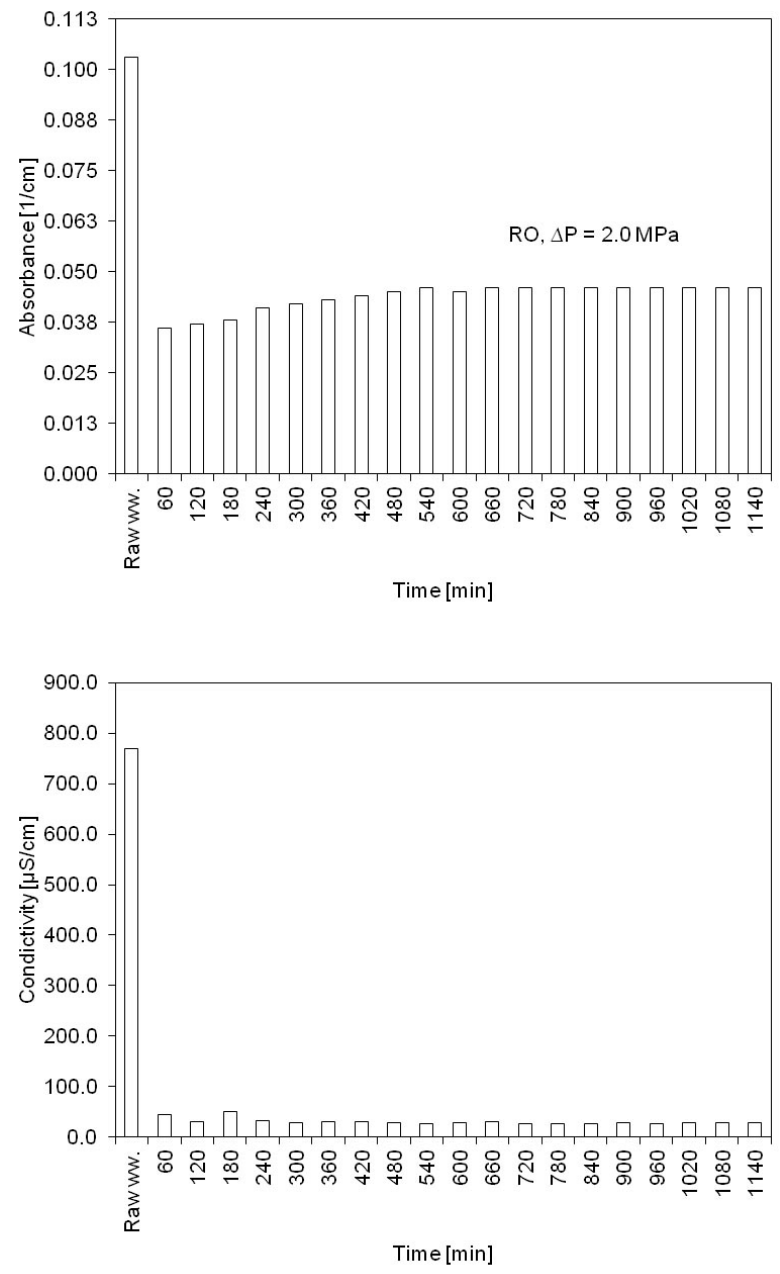

Figure 5. Efficiency of wastewater treatment through reverse osmosis

tion indicators such as total organic carbon and the phenolic index, decreased by approximately 95 and $91 \%$, respectively. After the reverse osmosis process, the concentrations of selected heavy metals were identified in the permeate, i.e., zinc, copper, lead, nickel chromium and mercury (Table 1). In this case, a wide variation in the extent of their elimination was documented. Among the tested heavy metals, only lead and chromium were completely removed. In turn, zinc, copper, nickel and mercury were eliminated by approximately $31,50,85$ and $75 \%$, respectively.

\section{CONCLUSION}

Wastewater purification through ultrafiltration/reverse osmosis demonstrated a high efficiency of pollutant removal, including the lowmolecular weight bisphenol A. A single ultrafiltration process is not effective at eliminating 
micropollutants. In the tested purification systems, ultrafiltration/reverse osmosis completely removed colour, lead and chromium. Other contaminants were eliminated by $31 \%$ or more. The application of the ultrafiltration process before reverse osmosis did not limit the occurrence of membrane pores being blocked.

\section{Acknowledgements}

The authors thank the National Center for Research and Development Poland for the financial support under Project No. POIR.01.01.01-00-0637/15.

\section{REFERENCES}

1. Anderson, J.C., Joudan, S., Shoichet, E., (...), Hanson, M.L., Wong, C.S., 2015, Reducing nutrients, organic micropollutants, antibiotic resistance, and toxicity in rural wastewater effluent with subsurface filtration treatment technology. Ecological Engineering, 84(11), 375-385.

2. Barbosa, M.O., Moreira, N.F.F., Ribeiro, A.R., Pereira, M.F.R., Silva A.M.T., 2016. Occurrence and removal of organic micropollutants: an overview of the watch list of EU decision 2015/495. Water Research, 94(5), 257-279.
3. Deblonde, T., Cossu-Leguille, C., Hartemann, P., 2011, Emerging pollutants in wastewater: a review of the literature. International Journal of Hygiene and Environmental Health, 214(11), 442-448.

4. Giannakis, S., Gamarra Vives, F.A., Grandjean, D., (...), De Alencastro, L.F., Pulgarin, C., 2015, Effect of advanced oxidation processes on the micropollutants and the effluent organic matter contained in municipal wastewater previously treated by three different secondary methods, Water Research, 84(11), 295-306.

5. Grandclément, C., Seyssiecq, I., Piram, A., WongWah-Chung, P., Vanot, G., Tiliacos, N., Roche, N., Doumenq, P., 2017. From the conventional biological wastewater treatment to hybrid processes, the evaluation of organic micropollutant removal: A review. Water Research, 111(3), 297-317.

6. Kim, M.-K., Zoh, K.-D., 2016. Occurrence and removals of micropollutants in water environment. Environmental Engineering Research, 21(4), 319-332.

7. Tang, F., Hu, H.-Y., Sun, L.-J., Sun, Y.-X., Shi, N., Crittenden, J.C., 2016. Fouling characteristics of reverse osmosis membranes at different positions of a full-scale plant for municipal wastewater reclamation. Water Research, 90(3), 329-336.

8. Yu, T., Meng, L., Zhao, Q.-B., Shi, Y., Hu, H.-Y., Lu, Y., 2017. Effects of chemical cleaning on RO membrane inorganic, organic and microbial foulant removal in a full-scale plant for municipal wastewater reclamation. Water Research, 113(4), 1-10. 